\title{
Technology-Based Professional Development: The Case of Elementary School Teachers in Belgrade
}

\author{
DOI: 10.7595/management.fon.2018.0029
}

\begin{abstract}
:
Research question: This paper investigated the correlation between the perceptions of strategies that affect professional development and the obstacles to successful implementation of technology-based professional development. Motivation: The research sought to determine elements that make professional development effective in the eyes of teachers, so that they may be more apt to use what they learn in classroom practice. The concept draws upon the TPACK framework while discussion and recommendations draw upon the UTAUT stages that teachers pass through when faced with new innovations. This study looks at the variables of a) time spent teaching, b) level of education, c) knowledge/use of computers, d) class preparation, and e) technology seminars of survey participants, to determine what demographical characteristics may have an impact on certain belief patterns surrounding professional development and technology use. Idea: The idea of this study is to look at the effectiveness of professional development to integrate technology into classroom practice and to allow for recommendations for improved technology-based professional development. Data: Data collected from a paper-based survey was completed by elementary school teachers in the school district of the city of Belgrade, Serbia. Tools: To explore possible correlations and to measure the strength of the relationship between nominal variables in this study, a non-parametric Spearman coefficient was used. Findings: This study has found that educational experiences and practice using technology do correlate with self-efficacy, willingness to use technology and active resistance of professional development experiences. Contribution: The results call for more technology support and communities of collaboration to implement effective professional development and may help educational leaders in Serbia to develop effective technology-based professional development programmes.
\end{abstract}

Keywords: TPACK, Preferences, Technology, Professional development, Technology-based training

JEL classifications: C14, C18, I20, I21, I24, I28, J24, L86

\section{Introduction}

Terek, Ivanovic, Terzic, Telek \& Scepanovic (2015) describe a state of educational reform in Serbia, dictated by appointments of new ministers, political climate, and scientific vision. These changes impact training and development of teachers, as methods and tools are in constant state of flux. As with many mandates, innovations such as technology integration go into law, with little focus on how to practically implement into an infrastructure that already exists. In Serbia, technology is one of those innovations that has been rapidly introduced into elementary schools, without professional development plans to support teachers in preservice education or classroom practice

Unfortunately, the truth of the matter as explained by Terek et al. (2015) is that higher education institutions have little control over what is taught in pre-service education, so the onus of preparing teachers for new innovations is placed upon in-service training and professional development at the schools. This study seeks to explore and analyze data from elementary school teachers in Belgrade, Serbia, regarding their experiences and preferences of technology-based professional development, and to provide support and recommendations for school-based training practices. 
Professional development provides the opportunity for teachers to be exposed to, practice, and obtain feedback on professional goals for intended change of pedagogy. It allows pedagogical and content experts to "recognize, accept, adapt, explore, and advance" technologies, hence should be based on teacher needs (Ndongfack, 2015a). The idea of pedagogical knowledge was first introduced by Shulman (1986), where it was determined that teachers develop a unique knowledge beyond the content areas, and show a development of understanding by learning content in a way that relates to how they are going to teach it. This knowledge includes understanding structure, organization, use, curriculum alignment, and placement of subsequent learning and steps. This study will draw upon an extension of Shulman's (1986) theory, a concept called the TPACK framework that includes technological, pedagogical, and content knowledge (Mishra \& Koehler, 2006). This framework describes professional development practices that allow teachers to implement learned skills into the classroom, and is often used to instigate professional development by integrating learning and practice of technology, alongside specific pedagogical and content uses. Accordingly, Terek et al. (2015) describe an alignment to the TPACK framework in that Serbian primary teachers are being held accountable for a truly multidisciplinary approach. In this, the knowledge of teachers spans across areas of subject expertise, curriculum and standards, pedagogical expertise, and innovation, research, and social and cultural needs of students. Without an all-encompassing framework of training for the purpose of teaching, teachers will falter, and not meet the needs of their students.

Historically, technology-based professional development trained on what the technology could do, and not necessarily on how to use it in practice, so this framework focuses on what is needed to effectively integrate technology to the classroom (Mishra \& Koehler, 2006; Koehler \& Mishra, 2009). In this framework, it is recommended that technology is used as a platform for professional development so that teachers gain experience with it first. When technology is utilized to implement professional development, this can provide self-confidence and support a higher rate of change (Kao, Tsai \& Shih, 2014). Effective professional development, according to teachers, is ongoing, addresses specific problems, supports collaboration, allows for lesson planning, and encourages observation and follow-up (Ndongfack, 2015a). When teachers buyin, and effectively interpret how technologies can be used to impact the student learning (Lochner, Conrad \& Graham, 2015), the effects can be widespread on student and cultural outcomes.

Variables impacting the adoption, integration, and sustainability of technology are often dependent upon attitudes, mastery, and engagement of stakeholders, which is coined as technology acceptance (Davis, 1989). Lochner et al. (2015) describe stages that teachers pass through before they truly accept a change: awareness, gathering information, personal impacts, management, consequences, collaboration, and refocusing. Teachers move through these stages during technology implementation, often beginning in avoidance, then considering personal impacts, gaining willingness, organizing information for practical application, and then finally, they work through the impacts of use, as they seek support for full implementation. To truly get to adapt and change, the idea of acceptance is important. Davis (1989) explored variables that could be measured to predict technology usage. From this groundbreaking study, it was determined that perceived usefulness was correlated with predicted future use, and ease of use was related to perceived usefulness. To avoid helplessness during any of the early stages, professional development should work through the technology processes, and focus on the value of the innovation.

In 2003, Venkatesh, Morris, Davis \& Davis (2003) attempted to unify the wide range of models on technology acceptance, and determined a distinct model called the Unified Theory of Acceptance and Use of Technology (UTAUT). This theory describes four areas of acceptance of technology, along with demographical variables that could impact prediction of use. These variables were: performance expectancy, effort expectancy, social influences, facilitating conditions, and variables included age, gender, voluntariness, and experience. The style or circumstances of perceptions of professional development, perceived usefulness, and obstacles for integration of technology into the classroom are essential in understanding implications that impact the transition to use technology in the classroom.

Matovic and Spasenovic (2016) explain that while Serbia has paved a path for professional development by requiring teachers to complete 120 points of in-service trainings to keep certifications, the types of in-service trainings are typically left to teachers' own initiative. The limited structure of professional development and seminar programmes that take too much time and funds, without clear results (Terek et al., 2015), could be a barrier to successful implementation. Furthermore, Matovic and Spasenovic (2016) stated that while the attendance to professional seminars has been a popular in-service training, it provides a gap for elementary school teachers who need more in-class practice of strategies. Hence, the goal of this research is to look at circumstances in a school district in Belgrade, Serbia, and to confirm experiences and perceptions of professional development in technology utilization. Exploring this information will allow for recommendations for improvement and acceptance of technology-based professional development. 


\section{Research Methodology}

For this study, a paper-based survey was submitted to teachers that questioned basic demographics, experiences with technology as a teaching tool, professional development experienced, preferences and beliefs regarding professional development, improvement of technology use, and obstacles to successful implementation of technology in the classroom. It included 61 teachers within six elementary schools in the school district of the city of Belgrade (municipalities of Lazarevac, Voždovac, and New Belgrade).

This exploratory study set out to determine if there were correlations among elements of data related to technology-based professional development and teacher experiences with technology. The following research questions helped guide the exploration of data: Is there a correlation between perceptions of strategies that impact professional development and obstacles to successful implementation of technologybased professional development, and a) time spent teaching, b) level of education, c) knowledge/use of computers, d) class preparation, and e) technology base seminars of survey participants?

The reliability of the survey was first tested for the groups of independent variables (demographics). Then the groups of questions about experiences (dependent variables) were also tested. In both cases, Cronbach Alpha was used as a measure of reliability (George \& Mallery, 2007). It showed a high level of reliability ( 0.803 for independent and 0.923 for dependent variables), meaning that the instrument used provides true representation of the measured sample.

\section{Results}

In the total number of participants $(n=61)$, there were $91.8 \%$ female teachers, and $8.2 \%$ male teachers. This shows that the employees in the field of education in the Belgrade school district are mostly female, which coincides with both national (Djordjevic, 2017) and worldwide trends (Eurostat, 2016; The World Bank, 2016). The largest number of participants (41\%) have worked as teachers for $8-15$ years, the smallest number (1\%) worked for 36 or more years. It can be said that most participants were mid-way through the career. The largest number of participants $(79 \%)$ had a bachelor degree, while the smallest number had associate degrees (3\%). The Master's degree is held by $21 \%$ of participants. In terms of a teaching field, the largest number of participants were teaching subjects in social sciences (56\%), while the smallest group was in the field of arts (3\%).

To explore possible correlations and to measure the strength of the relationship between variables, a nonparametric Spearman coefficient ( $\rho$, Greek letter rho) was used. Because variables measured in this study were nominal, nonparametric analysis was deemed appropriate. Correlation denotes the association between the two variables, so that a negative correlation represents a decrease in perceptions of values of one variable while the other variable increases. In addition, if probability value $p<0.05$ were found, it was considered a statistically significant relationship for a given statistical model (Tables 1-5).

Table 1: The impact of years of teaching on given variables

\begin{tabular}{|l|c|c|}
\hline Variable & Correlation & p-value \\
\hline Access to social media & -0.300 & 0.023 \\
\hline Using Social Media & -0.268 & 0.044 \\
\hline Knowledge of computer programs & -0.273 & 0.008 \\
\hline Using the Internet to prepare classes & -0.342 & 0.007 \\
\hline Learning from another person & -0.398 & 0.001 \\
\hline Learning from online courses & -0.314 & 0.014 \\
\hline Legal regulation need to change & -0.314 & 0.009 \\
\hline Lack of motivation as an obstacle & -0.348 & 0.006 \\
\hline
\end{tabular}

Source: Author's calculation 
Table 2: The impact of education level on given variables

\begin{tabular}{|l|c|c|}
\hline Variable & Correlation & p-value \\
\hline Knowledge of computer programs & 0.331 & 0.040 \\
\hline Using the Internet to prepare classes & 0.227 & 0.044 \\
\hline Learning form another person & 0.273 & 0.042 \\
\hline Formal degree & 0.221 & 0.024 \\
\hline Lack of motivation as an obstacle & 0.291 & 0.011 \\
\hline
\end{tabular}

Source: Author's calculation

Table 3: The impact of knowledge of computer programs on given variables

\begin{tabular}{|l|c|c|}
\hline Variable & Correlation & p-value \\
\hline Learning form another person & 0.255 & 0.048 \\
\hline Learning from online courses & 0.418 & 0.001 \\
\hline Promotion of online courses & 0.500 & 0.000 \\
\hline Teacher assessment system & 0.221 & 0.024 \\
\hline
\end{tabular}

Source: Author's calculation

Table 4: The impact of using technology to prepare lessons on given variables

\begin{tabular}{|l|c|c|}
\hline Variable & Correlation & p-value \\
\hline Built by independent knowledge & 0.338 & 0.008 \\
\hline PD by online courses & 0.279 & 0.044 \\
\hline Legal regulations need improvement & 0.340 & 0.007 \\
\hline Tech support improvements & 0.276 & 0.029 \\
\hline
\end{tabular}

Source: Author's calculation

Table 5: The impact of technology based seminars on given variables

\begin{tabular}{|l|c|c|}
\hline Variable & Correlation & p-value \\
\hline Technology support as obstacle & 0.227 & 0.013 \\
\hline Benefit from online courses & -0.312 & 0.010 \\
\hline
\end{tabular}

Source: Author's calculation

\section{Discussion}

Terek et al. (2015) explain that teachers in the beginning of their career have a keen focus on education law, accountability, teaching methods, certification, and student individual needs, and many schools in Serbia do not have the professional development capacity to meet the unique needs of beginning teachers, therefore creating a gap in the integration of methods learned directly to the classroom. A needs assessment conducted by Terek et al. (2015) on Serbian primary teachers highlighted the need for professional development on differentiation strategies, using modern methods in teaching and use of new technologies. These needs open the floor for the following discussion and recommendations.

As shown, veteran elementary teachers tend to use technology less, have less confidence, and less willingness to use and collaborate around technology. They are not using social media as often as teachers new to the career (Table 1), but when they do, they are likely to use it to exchange content with students as a teaching tool. This may support the use of co-teams of new and veteran teachers to share knowledge, processes and pedagogy when implementing technology into classroom practice. Duncombe \& Armour (2004) agree that collaborative professional learning makes continuing professional development more relevant. When teachers are grouped based on individual experiences and abilities, collaboration can be effective. From the Matovic \& Spasenovic (2016) study, Serbian elementary teachers included in the study felt most prepared from professional development when they could corroborate with experts, collaborate with 
colleagues, practice concepts in their classroom, and be given up-to-date literature. They did not feel prepared after attending conferences, or taking tours of schools. This request for school-based and taskbased trainings are concepts suggested by the TPACK method.

Veteran teachers tended to have a lower self-efficacy in their technical ability, which can be intensified due to change in educational mandates. As teachers progress through their career, they become less likely to use technology to prepare lessons, and become more resistant to change and collaboration with colleagues around technological skills (Table 1). Liu, Tsai \& Huang (2015) have found that pre-service teachers typically have more experience than in-service teachers in regard to the use of technology, while teachers later in their career have more experience with content and pedagogy. This shift in skills and expertise may call for a strong mentor programme as part of professional development. For primary school teachers in Serbia, there is a system set up for a two-year internship for all new teachers. This programme consists of inductions, exams to obtaining a licance, and being assigned a mentor (Terek et al., 2015). The mentor relationship includes sharing duties of student assessment, observation of lessons and lesson plans, and modelling of lessons to offer feedback. The problem is little guidance to this mentor programme, little training for mentors, and little accountability to benchmarks. With the recommendations from the TPACK method used, this mentorship programme could be re-invented and focus on professional development needs of elementary school teachers and to innovative approaches to teaching.

Professional development that utilizes the TPACK method of support, collaboration, and practice, could help share upon strengths of teachers in different stages of their career. To move teachers beyond resistance, it is recommended that professional development focus on concerns, and allow teachers to safely practice and integrate with confidence. This is addressed by Kannan \& Narayanan's (2015) research showing that the variables that had the most impact on teacher satisfaction with utilizing new technology were the effectiveness of the technology on classroom practice and behavioural intention to use the technology; all elements that can be practiced and built. Kadijevic, Haapasale \& Hvorecky (2005) conducted a study with elementary Math teachers from Finland, Serbia, and Slovakia to study the extent to which integration of technology from professional development was being utilized in class. This study found that the rate of interest in technology was indicative of utilization of the skills, and that interest was primarily influenced by the computer attitude. This lends toward professional development focusing on computer attitude of teachers, and "developing a strong positive relationship with technology" (p. 52). The TPACK framework supports this by: a) showing benefits of using technology in professional development (PD), b) allowing self-efficacy to build by practice and demonstration, c) allowing integration of technology into lesson plans, and d) working together to integrate technology into the curriculum by involving participants in true critical thinking (Ndongfack, 2015b). As data shows, this supports the notion that participants who develop better knowledge of computer programs through practice, will have more intention and motivation to learn from professional development (Table 3).

Teachers with less practice with technology tend to not want professional development of any form. This active resistance to change could be connected to performance expectancy, which outlines the degree to which someone believes that utilizing technology will help obtain gains in performance or cause struggles in their performance (Venkatesh et al., 2003). Those with more knowledge or experiences with online seminars tend to want more collaborative experiences, even though they still did not agree that online courses were the best method for professional development (Table 5). Participants that use technology to prepare lessons believed in online learning for personal benefit, but agreed more in legal regulations regarding teaching, needing further improvement (Table 4). Even with active experiences in learning online, until those experiences become utilized and comfortable in classroom application, individuals may resist learning in any format. Davis (1989), as well as Thompson, Higgins \& Howell (1991) suggested that users will be more inclined to accept technology if they find it useful to their job performance. If online seminars are the best professional development approach for a school, it is important to give participants the opportunity to utilize what they are learning in practice, and to clearly identify performance expectancy, in order to gain buy-in and motivation for the innovation.

With the application of technology becoming more common, teachers are becoming more open to technology communities, to using technology with students, and to overcoming fear of regulations and change. To impact motivation, it is recommended that leaders use collaboration, safe competition, and positive reinforcement to support teachers in changing their practice. Hebib, Spasenovic \& Saljic (2015) explain that Serbian elementary school teachers feel that positive feedback through teacher evaluation helps support the growth of teachers. The recommendation of tying PD to the teacher evaluation system could foster a feedback and impact self-efficacy. Accordingly, technology readiness and integration is made up of personal dispositions of optimism, innovativeness, perceived lack of control, and distrust. The more this 
professional development focuses on optimism and innovativeness, rather than feed into the inhibitors, the more likely it is that success will be achieved (Lin, Lin \& Lee, 2015).

Teachers who have not had a lot of practice in formal academic experiences could benefit from the use of consistent technology interactions and more time to practice. This concept may refer to the idea of effort expectancy, which is the degree of perceived ease when using new technologies (Venkatesh et al., 2003). The results from Table 2 show that teachers with more formal education tend to agree that they do not lack motivation to utilize technology, while teachers with less practice may. Tondeur, Kershaw, Vanderlinde \& van Brak (2013), and Murthy, lyer \& Warriem (2015) explain that collaboration with colleagues can impact effective integration of technology, as when learning technology is left to figure out on their own, this leads to ineffective solutions and isolation. In early stages of technology adoption, if teachers have not had adequate training or believe the benefits of the new technology outweigh the challenges, the expected (or anticipated) effort may become an obstacle (Davis, Bagozzi \& Warshaw, 1989). Teachers who may not have had formal experiences with technology may become more motivated when working with someone who has, on practical and useful projects.

If teachers have low self-efficacy for utilizing technology, this could turn them away from training and cause a feeling of helplessness. According to Slaouti \& Barton (2007), the Internet self-efficacy indicates selfperceived confidence, and unsuccessful experiences impact motivation towards future technology use. When teachers have high self-efficacy, they often interact in training, have higher probability of application to the classroom, and have less anxiety about collaboration (Kao et al., 2014). The construct of facilitating conditions in PD (constraints) is one that the institution can directly support to eliminate barriers and increase acceptance. In case of older teachers, it was found that facilitating conditions were especially important for increased use (Venkatesh \& Morris, 2000). For teachers struggling, if training is coupled with more technical support focusing on instruction, practice, and safe feedback, teacher confidence may be improved. The PD for struggling teachers should be housed in the school and focus on specific roles to practically and immediately apply what they learn, with support. To improve self-efficacy, teachers need an opportunity to master technology changes so that they can be supported and develop more confidence.

It has been documented that teachers' sense of personal ability determined how they handled the challenge of integrating new technology (Cervera \& Cantabrana, 2015), while perceived self-efficacy and computer anxiety are often predictors of technology use (Machado a\& Chung, 2015). These efficacy issues may impact the teachers' image or status if they are perceived to be incompetent. Social influence is the perception that teachers may have about how they look and whether "important" people believe they should use the new technology (Venkatesh et. al, 2003; Taylor \& Todd, 1995). This is impacted by the perception of volunteering to use the innovative strategy, versus being "forced" to use it.

Educational leaders should be aware that resistant behaviours may show a link to low self-efficacy. Active resistance often comes in the form of ignoring resources, mandates, complaining about technical support, etc. These are usually teachers that need more hands on, school-based and supportive professional development, because teachers with a positive perception of improving their own teaching ability, persevere in innovative activities (Cervera \& Cantabrana, 2015). Supportive professional development should therefore include: training topics developed from school needs and results, teacher choice in how the innovation is used, technical support for clearer implementation, direct alignment to the teacher assessment system so that feedback and praise can be included, and development of a positive outlook of change within the organizational culture.

\section{Conclusion}

With the understanding that teachers in Belgrade, Serbia, may have limited opportunities for professional development that matches personal and school needs, the following suggestions are recommended for school leaders to implement schoolbased PD opportunities around changing technology innovation and demands. Rogers (1962) describes a series of characteristics that support the adoption of new innovations and behaviour within a social system, called the diffusion of innovation. It was determined that individuals who will accept early on, are associated with certain characteristics of a population. It is essential for leaders to determine who will be the ones supporting the innovation, versus the ones that will struggle. After this is determined, Rogers (1962) supported a series of factors that leaders can use to limit the obstacles of acceptance including: supporting advantages of the improvement, tying the innovation to the values, mission, and social environment, training to overcome complexities with the technology, allowing for testing and experimenting in a supportive environment, and clearly observing positive results. The failure to apply technology into the classroom once it 
is diffused can be mitigated through the use of the TPACK method, where teachers learn to integrate technological knowledge (TK) into their existing pedagogical (PK) and content knowledge (CK), to create understanding and practical application of technology use within their personal teaching methods.

Based on the data collected, the teacher's perceptions about using technology in the classroom, support the need for effective professional development. Terek at al. (2015) suggest a shortfall in primary school teacher professional development for elementary school teachers in Serbia, in that programmes are limited, and are not often based on individual and school needs and innovations. By keeping professional development as a school-focused activity, training can get directly to individual needs and plans. To be considered effective, it is recommended that collaborative professional development experiences be used to integrate technology, and to allow new and veteran teachers to collaborate together (Duncombe \& Armour, 2004; Tondeur et al., 2013). Furthermore, Duncombe \& Armour (2004) conducted a review of the literature on professional development and collaboration, and offered the most highly researched concepts for collaboration which included mentoring, peer coaching, critical friends, collegiality, observation, and resource sharing. Collaboration included through mentors, professional learning communities and observation are best practices that leaders could integrate to increase self-efficacy, and therefore, teacher performance (Burgoon, Meece \& Granger, 2012). Shea \& Bidjerano (2010) maintain that providing more opportunity for teachers with varying levels of experiences to work together and to engage with online activities, allows for practice and comfort with new technology. Effective professional development allows teachers to access resources and meet individual needs and schedules (Ndongfack, 2015a).

It is recommended that online professional development sessions are shortened and give teachers the opportunity to use examples from their own teaching domain, to implement strategies first for practice, then to teach strategies for pedagogical uses, to provide opportunities for follow-up (Ndongfack, 2015a), and to give practice in both the student and instructor roles of the new technology (Murthy et al., 2015). To support the use of the strategies learned, the technology must be readily available to teachers, so they can immediately apply knowledge (Shaha, Glassett, Copas \& Ellsworth, 2015). Depending on teacher experiences, professional development should focus on optimism and minimizing insecurities (Lin et al., 2015). This can be done through experience sharing seminars, verbal and written reflections, and ensuring that professional learning contexts and follow up always take place after professional training (Prestridge \& Tondeur, 2015).

\section{REFERENCES}

[1] Burgoon, J. M., Meece, J. L., \& Granger, N. A. (2012). Self-efficacy's influence on student academic achievement in the medical anatomy curriculum. Anatomical Sciences Education, 5(5), 249-255. DOI: $10.1002 / a s e .1283$

[2] Cervera, M., \& Cantabrana, J. (2015). Professional development in teacher digital competence and improving school quality from the teachers' perspective: A case study. New Approaches in Educational Research, 4 (2), 115-122. DOI: 10.7821/naer.2015.7.123

[3] Davis, F. (1989). Perceived usefulness, perceived ease of use, and user acceptance of information technology. MIS Quarterly, 13(3), 319-340. DOI: 10.2307/249008

[4] Davis, F., Bagozzi, R., \& Warshaw, P. (1989). User acceptance of computer technology: A comparison of two theoretical models. Management Science, 35(8), 982-1003.

[5] Djordjevic V. (2017). Feminizacija prosvete. Srpski kulturni klub. Retrieved from: http://скк.срб/2017/05/30/vladislav-djordjevic-feminizacija-prosvete/

[6] Duncombe, R., \& Armour, K. (2004). Collaborative professional learning: From theory to practice. Journal of In-Service Education, 30(1), 141-166. DOI: 10.1080/13674580400200230

[7] Eurostat (2016). Women teachers largely over-represented in primary education in the EU. Retrieved from: http://ec.europa.eu/eurostat/documents/2995521/7672738/3-04102016-BP-EN.pdf/9fOd2d04211a-487d-87c3-0a5f7d6b22ce

[8] George, D., \& Mallery, P. (2007). SPSS for WINDOWS Step by Step: A simple guide and reference. Pearson, 222-223.

[9] Hebib, E., Spasenovic, V., \& Saljic, Z. (2015). Evaluation of school education in Serbia. Education Policy, Reforms \& School Leadership, 198-204.

[10] Kadijevic, D., Haapasale, L., \& Hvorecky, J. (2005). Educational technology standards in professional development of mathematics teachers: An international study. The Teaching of Mathematics; 8(1), 47-52.

[11] Kannan, K., \& Narayanan, K. (2015). A Structural Equation Modelling Approach for Massive Blended Synchronous Teacher Training. Educational Technology \& Society, 18 (3), 115.

[12] Kao, C.-P., Tsai, C.-C., \& Shih, M. (2014). Development of a Survey to Measure Self-efficacy and Attitudes toward Web-based Professional Development among Elementary School Teachers. Educational Technology \& Society, 17 (4), 302-315.

[13] Koehler; M.J., \& Mishra, P. (2009). What is technological pedagogical content knowledge? Contemporary Issues in Technology and Teacher Education, 9(1), 60-70.

DOI: $10.1177 / 002205741319300303$ 
[14] Lin, S., Lin, C., \& Lee, D. (2015). The relationship between elementary school teachers' technology readiness and intention to use social media platforms for classroom management. International Journal of Organizational Innovation, 8 (1), 48-63.

[15] Liu, S. H., Tsai, H. C., \& Huang, Y. T. (2015). Collaborative Professional Development of Mentor Teachers and Pre-Service Teachers in Relation to Technology Integration. Educational Technology \& Society, 18 (3), 161-172.

[16] Lochner, B., Conrad, R., \& Graham, E. (2015). Secondary teachers' concerns in adopting learning management systems: A U.S. perspective. TechTrends, 59 (5), 62-70. DOI: 10.1007/s11528-0150892-4

[17] Machado, L., \& Chung, C. (2015). Integrating technology: The principals' role and effect. International Education Studies, 8 (5), 43-53. DOI: 10.5539/ies.v8n5p43

[18] Matovic, N., \& Spasenovic, V. (2016). Teacher professional development in the field of inclusive education: The case of Serbia. Journal of Contemporary Educational Studies, 1, 38-53.

[19] . Technological Pedagogical Content Knowledge: A framework for teacher knowledge. Teachers College Record, 108(6), 1017-1054. DOI: 10.1111/j.1467-9620.2006.00684.x

[20] Murthy, S., lyer, S., \& Warriem, J. (2015). ET4ET: A Large-Scale Faculty Professional Development Program on Effective Integration of Educational Technology. Educational Technology \& Society, 18 (3), 16-28.

[21] Ndongfack, M. (2015a). Mastery of Active and Shared Learning Processes for Techno-Pedagogy (MASLEPT): A Model for Teacher Professional Development on Technology Integration. Creative Education, 6, 32-45.

[22] Ndongfack, M. (2015b). TPACK Constructs: A Sustainable Pathway for Teachers Professional Development on Technology Adoption. Creative Education, 6, 1697-1709.

[23] Prestridge, S., \& Tondeur, J. (2015). Exploring elements that support teachers engagement in online professional development. Education Sciences, 5, 199-219. DOI: 10.3390/educsci5030199

[24] Rogers, E. (1962). Diffusion of Innovations. New York, NY: Free Press.

[25] Shaha, S., Glassett, K., Copas, A., \& Ellsworth, H. (2015). Title I schools: The student-based impact of online, on-demand professional development on educators. Contemporary Issues in Education Research, 8 (4), 227-234.

[26] Shea, P., \& Bidjerano, T. (2010). Learning presence: Towards a theory of self-efficacy, self regulation, and the development of a communities of inquiry in online and blended learning environments. Computers \& Education, 55(4),1721-1731. DOI: 10.1016/j.compedu.2010.07.017

[27] Shulman, L. (1986). Those who understand: Knowledge growth in teaching. Educational Researcher, 15, 4-14. DOI: 10.3102/0013189X015002004

[28] Slaouti, D., \& Barton, A. (2007). Opportunities for practice and development: Newly qualified teachers and the use of information and communications technologies in teaching foreign languages in English secondary school contexts. Journal of In-service Education, 33(4),405-424. DOI: 10.1080/13674580701687807

[29] Taylor, S., \& Todd, P. (1995). Assessing IT usage: The role of prior experience. MIS Quarterly, 19, 561570. DOI: $10.2307 / 249633$

[30] Terek, L, Ivanovic, A., Terzic, I, Telek, K., \& Scepanovic, N. (2015). Professional development for programs as a support for teachers at the beginning of their career. Croatian Journal of Education; 17(2),137-158. DOI: 10.3102/0013189X015002004

[31] The World Bank (2016). Primary education teachers, \% female. UNESCO Institute for Statistics. Retrieved from: https://data.worldbank.org/indicator/SE.PRM.TCHR.FE.ZS

[32] Thompson, R., Higgins, C., \& Howell, J. (1991). Personal computing: Toward a conceptual model of utilization. MIS Quarterly, 15, 124-143. DOI: 10.2307/249443

[33] Tondeur, J., Kershaw, L. H., Vanderlinde, R. R., \& van Braak, J. (2013). Getting inside the black box of technology integration in education: Teachers' stimulated recall of classroom observations. Australasian Journal of Educational Technology, 29(3), 434-449. DOI: 10.14742/ajet.16

[34] Venkatesh, V., Morris, M., Davis, G., \& Davis, F. (2003). User acceptance of information technology: Toward a unified view. MIS Quarterly, 27(3), 425-478. DOI: $10.2307 / 30036540$

[35] Venkatesh, V., \& Morris, M. (2000). Why don't men ever stop to ask for directions? Gender, social influence, and their role in technology acceptance and usage behavior. MIS Quarterly, 24(1), 115-139. DOI: $10.2307 / 3250981$ 


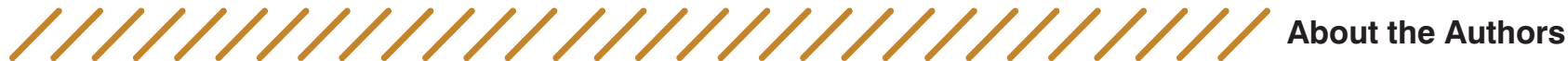

\section{Mirjana Joksimović \\ Elementary school "Diša Đurđević", Vreoci-Lazarevac, Serbia ivajoks@gmail.com}

Mirjana Joksimović, MSc, is the principal of elementary school "Diša Đurđević". She graduated from the Faculty of Pedagogy for Teacher Education, University of Belgrade, and completed her Master's degree in Engineering Management program at the

Singidunum University. Under the auspices of the Ministry of Education, Science and

Technological Development of the Republic of Serbia, she has been engaged in the training programme and obtained a license to work as the principal of the school. She is currently engaged in mentoring and human development program in the school, as a part of Tempus program on Leadership in Education.

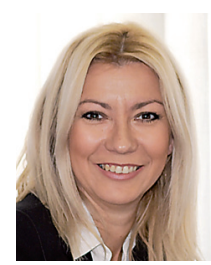

\section{Ashlee Robertson}

Keiser University, Education Faculty, USA

arobertson@keiseruniversity.edy

Ashlee Robertson, $\mathrm{PhD}$, is a graduate school professor at Keiser University in Florida, USA, for the PhD education departments of Educational Leadership,

Curriculum and Instruction and Instructional Design. Her PhD is in curriculum and instruction, and her professional expertise and experience is in $\mathrm{K}-12$ teaching, school administration and instructional design.

\section{Borivoje Đokić \\ Keiser University, Business Faculty, USA bdjokic@keiseruniversity.edy}

Borivoje Đokić, PhD, is a graduate school professor at Keiser University in Florida, USA, for the MBA and DBA programmes of business department, areas of quantitative analysis and business research methods. His professional expertise includes performing applied research at the University of Miami,

School of Medicine and computer and biostatistics support for the department of Pediatrics of University of Miami, School of Medicine.
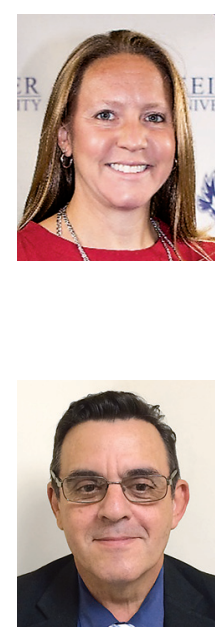

Lazar Dražeta Singidunum University, Serbia Idrazeta@singidunum.ac.rs

Lazar Dražeta, PhD, works as Assistant Professor and Coordinator of the Singidunum University Institute. He is involved in teaching at bachelor and master programmes as well as business consulting in the area of human resource management. His previous work experience includes a number of corporate sales and human resource functions, both in Serbia and overseas.

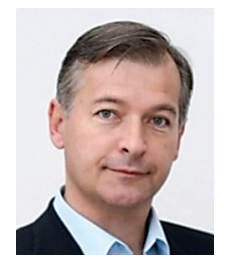

